\title{
O SIGAA NA FORMAÇÃO DISCENTE: ESTUDO DE CASO NOS CURSOS DA UFRR
}

\section{ARTIGO ORIGINAL}

ASSIS, Sara Protásio ${ }^{1}$

ASSIS, Sara Protásio. O SIGAA na formação discente: Estudo de caso nos cursos da UFRR. Revista Científica Multidisciplinar Núcleo do Conhecimento. Ano 05, Ed. 05, Vol. 12, pp. 128-137. Maio de 2020. ISSN: 2448-0959, Link de acesso: https://www.nucleodoconhecimento.com.br/educacao/sigaa-na-formacao

\section{RESUMO}

O Sistema Integrado de Gestão de Atividades Acadêmicas (SIGAA) da Universidade Federal de Roraima (UFRR) é uma plataforma online disponível para a comunidade institucional que busca facilitar a comunicação e principalmente estreitar a relação professor-aluno, potencializando assim o processo ensino-aprendizagem na formação acadêmica. O presente trabalho teve como objetivo avaliar a eficácia e a utilização da plataforma SIGAA no processo de formação acadêmica do discente de graduação da Universidade Federal de Roraima - UFRR. Realizou-se uma pesquisa bibliográfica para um melhor embasamento teórico por meio de artigos, considerando as contribuições de autores como FILHO et al. (2013), LOPES et al. (2018), SOUZA e MONTEIRO (2015), leis como a Constituição Federal do Brasil (1988), Lei de Diretrizes e Bases no 9.394/96, procurando enfatizar a importância da plataforma para

\footnotetext{
1 Especialização em Tutoria em Educação a Distância e Docência do Ensino Superior, pela Universidade Única/Instituto Prominas - Minas Gerais/2019. Graduação em Licenciatura em Letras com ênfase em Espanhol e Literatura Hispânica, pelo Instituto Federal de Educação, Ciência e Tecnologia de Roraima/2016. Cursando graduação em Engenharia Elétrica, pela Universidade Federal de Roraima. Técnico em Radiologia com ênfase em Radiodiagnóstico, pelo Instituto Federal de Educação, Ciência e Tecnologia de Roraima/2011.
} 
o meio acadêmico. Realizou-se uma abordagem qualitativa, adquiridas por meio de método de campo, com a aplicação de um questionário estruturado com discentes dos cursos de Graduação da UFRR, Campus Paricarana. Segundo os participantes, a avaliação do SIGAA em termos de usabilidade para estudo, foi considerada como boa e ótima. Porém, a plataforma possui muitas ferramentas que nunca foram utilizadas pelos alunos. Sugerindo-se que a Universidade Federal de Roraima adote um processo gerencial e avaliativo a fim de aprimorar os recursos do SIGAA, o que permitirá o avanço no relacionamento professor-aluno/aluno-aluno e a melhoria do processo ensino-aprendizagem.

Palavras-chave: Sigaa, comunicação, formaç̧ão, plataforma, acadêmico.

\section{INTRODUÇÃO}

As ferramentas tecnológicas têm papel fundamental de inserção do indivíduo no sistema educacional e organizacional, pensando nisso criou-se o SIGAA (Sistema Integrado de Gestão de Atividades Acadêmicas), uma plataforma de interação acadêmica entre professor/aluno.

Segundo Filho et al. (2013), o SIGAA mobile possui funcionalidades como: compartilhamento de arquivos diretamente na turma virtual a partir do dispositivo, recebimento de mensagens, publicações de notas, tarefas e notificações como: datas de provas, prazo de trabalhos/tarefas e comunicação em grupo possibilitando a interação entre os alunos e participantes.

O texto final foi fundamentado nas ideias e concepções de autores como: Filho et al. (2013), Lopes et al. (2018), Souza e Monteiro (2015), leis como a Constituição Federal do Brasil (1988), Lei de Diretrizes e Bases no 9.394/96.

\section{DESENVOLVIMENTO}

De acordo com a Constituição (1988), a educação é um dever do estado e direito básico fundamental que todo cidadão possui. Quanto à educação: 
Art. 205. A educação, direito de todos e dever do Estado e da família, será promovida e incentivada com a colaboração da sociedade, visando ao pleno desenvolvimento da pessoa, seu preparo para o exercício da cidadania e sua qualificação para o trabalho.

Art. 206. O ensino será ministrado com base nos seguintes princípios:

I - igualdade de condições para o acesso e permanência na escola;

II - liberdade de aprender, ensinar, pesquisar e divulgar o pensamento, a arte e o saber;

III - pluralismo de ideias e de concepções pedagógicas, e coexistência de instituições públicas e privadas de ensino;

IV - gratuidade do ensino público em estabelecimentos oficiais;

V - valorização dos profissionais da educação escolar, garantidos, na forma da lei, planos de carreira, com ingresso exclusivamente por concurso público de provas e títulos, aos das redes públicas; (Redação dada pela Emenda Constitucional ํㅜ 53, de 2006)

VI - gestão democrática do ensino público, na forma da lei;

VII - garantia de padrão de qualidade.

VIII - piso salarial profissional nacional para os profissionais da educação escolar pública, nos termos de lei federal. (Incluído pela Emenda Constitucional ํㅜ 53, de 2006) (CONSTITUIÇÃO FEDERAL DO BRASIL, 1988)

Partindo do pressuposto dos artigos acima da Constituição Federal do Brasil, esta pesquisa objetiva trabalhar o sigaa, uma ferramenta acessível a todos no meio acadêmico, seja pelo computador, ou dispositivos móveis, tais como: celular ou tablet, independente da hora ou lugar. 
Corrobora também com a ideia acima o art. $1^{\circ}$ da Lei de Diretrizes e Bases - Lei nº 9.394/96:

A educação abrange os processos formativos que se desenvolvem na vida familiar, na convivência humana, no trabalho, nas instituições de ensino e pesquisa, nos movimentos sociais e organizações da sociedade civil e nas manifestações culturais. (LEI no 9.394/96)

No que tange a educação à distância, o art. 80 da Lei de Diretrizes e Bases - Lei no 9.394/96: "O Poder Público incentivará o desenvolvimento e a veiculação de programas de ensino a distância, em todos os níveis e modalidades de ensino, e de educação continuada".

O objetivo primordial deste estudo é avaliar a eficácia e a utilização da plataforma SIGAA no processo de formação acadêmica do discente de graduação da Universidade Federal de Roraima - UFRR.

Segundo Lopes et al. (2018) a utilização de recursos como as plataformas virtuais nas instituições de ensino, facilitam e melhoram a qualidade da aprendizagem humana, contribuindo para a alfabetização tecnológica, servindo como um recurso adicional ao processo de aprendizagem.

O Sistema Integrado de Gestão de Atividades Acadêmicas (SIGAA) informatiza os procedimentos da área acadêmica através de todos os módulos de ensino, submissão e controle de projetos e bolsistas, de pesquisa, de ações de extensão, e dos projetos de ensino (monitoria e inovações), registro e relatórios da produção acadêmica dos docentes, atividades de ensino a distância e é um ambiente virtual de aprendizado denominado Turma Virtual.

Segundo Souza e Monteiro (2015) o Sistema Integrado de Gestão de Atividades Acadêmicas foi produzido pela Universidade Federal do Rio Grande do Norte em 2007. Ainda segundo Souza e Monteiro (2015) tal sistema é detentor de ampla utilização no meio acadêmico, tanto para professores quanto para alunos. 
Após o surgimento do SIGAA em meados de 2007, a plataforma mudou o paradigma da gestão de processos internos e externos das Universidades, pois a Universidade intensificou a informatização da gestão com um conjunto de sistema, substituindo uma quantidade de etapas físicas e presenciais decorrentes de demandas de alunos e docentes.

Segundo Souza e Monteiro (2015):

O SIGAA traz um conjunto de unidades e serviços para a comunidade acadêmica, com o propósito de diminuir o tempo de operação das atividades mediante automação de atividades acadêmicas, entre estas, unifica os processos intrínsecos às atividades de ensino, pesquisa e extensão, além de outras atividades acadêmicas. (SOUZA e MONTEIRO, 2015, p. 615)

O SIGAA é uma ferramenta que veio para auxiliar e simplificar o preenchimento de notas, frequência, plano de aula, entre outras, permitindo mais tempo à produção de conteúdo das suas aulas, à projetos de pesquisa e de extensão. Para o discente, facilita o acesso às informações das turmas, das disciplinas e das atividades de sala de aulas.

Como forma de exemplificar segue abaixo imagem da plataforma.

Figura 1- Página inicial da plataforma SIGAA.

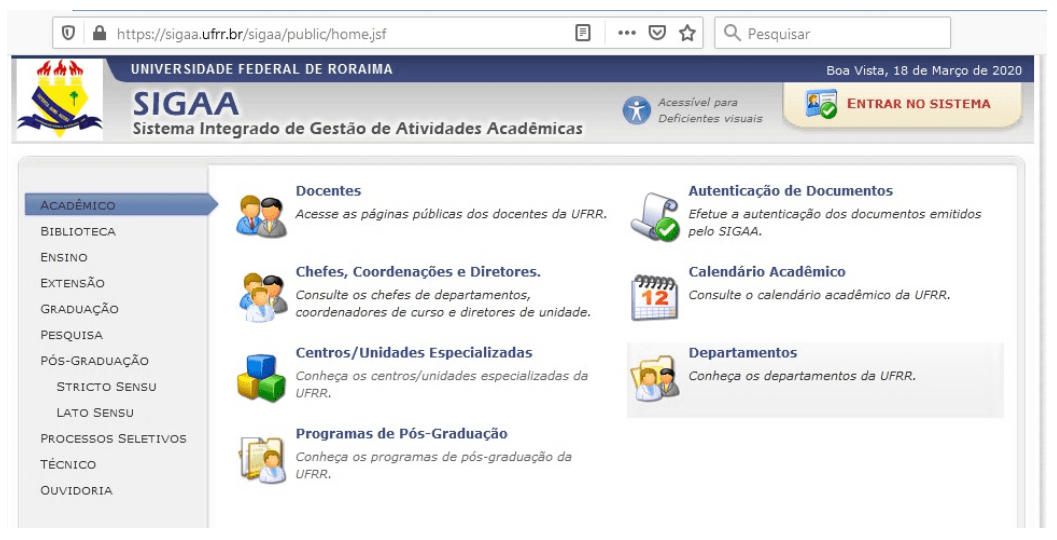

Fonte: Retirado da internet. 
Figura 2- Vista panorâmica dos ícones da plataforma SIGAA.

(1) O https://sigaa.ufr.br/sigaa/portais/discente/discente.jsf $\quad$ 目

\begin{tabular}{|c|c|c|c|c|}
\hline \multirow{2}{*}{$\begin{array}{l}\text { SARA PROTASIO ASSIS Alterar vinculo } \\
\text { CENTRO DE CIENCIAS E TECNOLOGIA (11.05) }\end{array}$} & \multirow[t]{2}{*}{ Semestre atual: 2020.1} & Dódulos & (1) Caixa Postal & Abrir Chamado Menu Discente \\
\hline & & \& Alterar senha & C) Ajuda & \\
\hline
\end{tabular}

Fonte: Retirado da internet.

\subsection{UM BREVE HISTÓRICO DA UNIVERSIDADE FEDERAL DE RORAIMA}

A UFRR foi implantada em 1989, quatro anos após ter sido autorizada pela Lei no $7.364 / 85$, foi a primeira instituição federal de ensino Superior a instalar-se em Roraima.

A instituição desenvolve, em parceria com o Governo Federal, ações constantes relacionadas à internacionalização do ensino, recebendo alunos de outros continentes e enviando seus acadêmicos para estudar fora do País. Tem atualmente núcleos e unidades de pesquisa em várias áreas de atuação.

\section{METODOLOGIA}

A abordagem adotada foi a qualitativa, devido a obtenção das informações serem subjetivas e adquiridas por meio da pesquisa de campo.

A pesquisa qualitativa "faz referências a seus fundamentos epistemológicos do que propriamente a especificidades metodológicas". (SEVERINO, 2007, p. 119).

Na pesquisa de campo "o objeto/fonte é abordado em seu meio ambiente próprio". (SEVERINO, 2007, p. 122).

A pesquisa está delineada como sendo uma pesquisa de campo, na qual se fez necessário ir buscar informação em um campo específico, no caso pessoas que vivenciam a plataforma Sigaa. Classificando-se também, como um estudo de caso 
devido o foco da pesquisa estar centrado no Sistema Integrado de Gestão de Ações Acadêmicas (Sigaa), da UFRR.

No estudo de caso "os dados devem ser coletados e registrados com o necessário rigor, trabalhados, mediante análise rigorosa, e apresentados em relatórios qualificados". (SEVERINO, 2007, p. 121).

A pesquisa foi realizada com o grupo acadêmico do Campus Paricarana da Universidade Federal de Roraima, localizada no município de Boa Vista, Capital do Estado de Roraima. A referida Universidade conta hoje com 47 (quarenta e sete) Cursos Superiores entre Tecnológico, Licenciaturas e Bacharelados, distribuídos entre 3 (três) Campus: Paricarana, Cauamé e Murupu. Porém, nesta pesquisa, nosso foco é apenas o Campus Paricarana.

A coleta dos dados ocorreu mediante a aplicação de um questionário por meio do Google Forms, que é um serviço gratuito para criar formulários online. Nele o usuário pode produzir pesquisas de múltipla escolha, fazer questões discursivas, solicitar avaliações em escala numérica e outros.

questionário foi do tipo estruturado, contendo questões abertas, fechadas e padronizadas, com número variável de alternativas fixas, sobre a utilização da plataforma SIGAA e de recursos durante os trabalhos da graduação, e avaliação da eficácia do sistema para a formação acadêmica.

Após a aplicação do questionário, os dados obtidos sobre os graduandos foram incluídos em planilhas de estudo e posteriormente postas em tabelas. O questionário foi aplicado no início do mês de junho de 2019 aos graduandos da UFRR.

\subsection{RESULTADOS}

Ao final da aplicação do questionário, a amostra em estudo foi constituída de um total de 41 graduandos participantes, distribuídos da seguinte maneira: 2 do curso de Arquitetura e Urbanismo (4,88\%), 1 do curso de Administração (2,44\%), 1 do curso de Economia (2,44\%), 1 do curso de Letras - Inglês (2,44\%), 4 do curso de Artes Visuais 
(9,76\%), 12 do curso de Engenharia Elétrica $(29,27 \%), 3$ do curso de Matemática (7,32\%), 1 do curso de Química (2,44\%), 4 do curso de Ciência da Computação $(9,76 \%), 1$ do curso de Letras - Literatura (2,44\%), 3 do curso de Medicina Veterinária (7,32\%), 1 do curso de Letras - Português (2,44\%), 1 do curso de História $(2,44 \%), 1$ do curso de Direito (2,44\%), 4 do curso de Engenharia Civil (9,76\%), 1 do curso de Física (2,44\%).

Dentre os participantes $53,7 \%$ eram do sexo masculino e $46,3 \%$ eram do sexo feminino.

Com relação à frequência que utilizam a plataforma SIGAA, 19 graduandos disseram que sempre a utilizam (46,3\%), 17 graduandos disseram que quase sempre a utilizam $(41,5 \%), 5$ graduandos disseram que raramente a utilizam (12,2\%).

Tabela 1. Distribuição quanto à frequência de utilização da plataforma SIGAA pelos discentes, na UFRR, Campus Paricarana.

\begin{tabular}{|l|l|}
\hline Itens Utilizados & \\
\hline Sempre & $19(46,3 \%)$ \\
\hline Quase sempre & $17(41,5 \%)$ \\
\hline Raramente & $5(12,2 \%)$ \\
\hline Nunca & - \\
\hline TOTAL & $41(100 \%)$ \\
\hline
\end{tabular}

Fonte: Pesquisa direta, 2019.

Os dados acima mostram que uma parcela significativa (46,3\%) sempre e $(41,5 \%)$ quase sempre utiliza a plataforma como forma de comunicação, visto que nos dias atuais, os docentes e os próprios acadêmicos optam por enviar/receber o material de apoio da disciplina por meio de grupos de aplicativos de mensagens instantâneas e/ou no pendrive.

Com relação aos recursos disponíveis na plataforma Sigaa (questão em que o aluno podia selecionar uma ou mais opções de respostas), dos 41 graduandos entrevistados 
37 responderam que utilizam a disciplina do componente curricular $(90,2 \%), 20$ responderam que utilizam a ferramenta ensino $(48,8 \%), 15$ responderam que utilizam a ferramenta biblioteca pela plataforma $(36,6 \%), 2$ responderam que utilizam o chat do sigaa $(4,9 \%)$ e 2 responderam que utilizam a ferramenta monitoria $(4,9 \%)$.

Tabela 2. Distribuição quanto a utilização dos recursos disponíveis na plataforma SIGAA pelos discentes, na UFRR, Campus Paricarana.

Recursos disponíveis

\begin{tabular}{|l|l|}
\hline Disciplina do componente curricular & $90,2 \%$ \\
\hline Ensino & $48,8 \%$ \\
\hline Biblioteca & $36,6 \%$ \\
\hline Chat & $4,9 \%$ \\
\hline Monitoria & $4,9 \%$ \\
\hline
\end{tabular}

Fonte: Pesquisa direta, 2019.

Os dados acima mostram que 90,2\% dos entrevistados utilizam a opção "disciplina do componente curricular", pois nessa opção é possível acompanhar as últimas atualizações publicadas pelos docentes, o material de apoio das disciplinas, as frequências/faltas, notas, fóruns, plano de curso, visualizar todos os participantes da disciplina.

A opção "ensino" também é muito utilizada, pois nela é possível emitir atestado de matrícula, emitir histórico, emitir declaração de vínculo, fazer a avaliação institucional a cada fim de semestre como pré-requisito para se matricular no semestre seguinte, realizar a matrícula on-line, pois facilita e evita filas intermináveis e papéis, o que é ecologicamente correto.

Em "ensino" também é possível trancar disciplinas, consultar turmas do semestre seguinte, visualizar o calendário acadêmico, consultas gerais, que incluem outras disciplinas e outros cursos. Essa opção é muito utilizada durante todo o semestre pelos discentes. 
A opção "biblioteca", não menos importante, possibilita cadastrar-se para utilizar os serviços da biblioteca, tais como: pesquisar materiais e artigos no acervo, realizar empréstimos ativos e renovar empréstimos, verificar situação/emitir documento de quitação, fazer reserva de materiais, quando há poucos exemplares do material desejado.

As opções com menos utilização pelos alunos foram o chat e a monitoria, talvez por dificuldade em utilizar tais recursos ou por resistência dos próprios docentes e discentes.

Com relação à avaliação da eficácia da plataforma Sigaa, dos 41 entrevistados, 4 responderam que ela é excelente $(9,75 \%), 12$ responderam que ela é ótima $(29,27 \%)$, 13 responderam que ela é boa $(31,71 \%), 9$ responderam que ela é regular $(21,95 \%)$, e 3 responderam que ela é péssima $(7,31 \%)$.

Tabela 3. Avaliação da eficácia da plataforma SIGAA pelos discentes, na UFRR, Campus Paricarana.

\begin{tabular}{|l|l|}
\hline Eficácia & \\
\hline Excelente & $9,75 \%$ \\
\hline Ótima & $29,27 \%$ \\
\hline Boa & $31,71 \%$ \\
\hline Regular & $21,95 \%$ \\
\hline Péssima & $7,31 \%$ \\
\hline Total & $100 \%$ \\
\hline
\end{tabular}

Fonte: Pesquisa direta, 2019.

\section{CONSIDERAÇÕES FINAIS}

No que tange a utilização da plataforma SIGAA pelos docentes e discentes como ferramenta de comunicação e de ensino-aprendizagem, constatou-se que há a utilização fluente da mesma por muitas instituições. 
Há o mau uso de outras ferramentas da plataforma por parte destes, a minoria solicita atendimento de monitoria por meio do sistema e o chat são os recursos menos utilizados pelos alunos. Esses últimos dados refletem a falta de conhecimento técnico no uso do chat pela maioria dos usuários, o que compromete a aceitação desse recurso de comunicação pelos discentes e até pelos docentes.

A plataforma SIGAA veio para trazer muitos benefícios para a comunidade universitária, tais como: compartilhamento de arquivos na turma virtual a partir do dispositivo, recebimento de mensagens, publicações de notas e tarefas, data de provas, prazo de trabalhos/tarefas e aproximação do limite de faltas.

Espera-se que tal pesquisa forneça contribuições futuras aos pesquisadores em geral para uma melhor aplicabilidade de tal plataforma, fazendo com que os professores e alunos possam usufruir de uma gama maior de recursos da plataforma sem tanta dificuldade, pois ela permite o avanço no relacionamento professor-aluno/aluno-aluno e a melhoria do processo ensino-aprendizagem.

\section{REFERÊNCIAS}

BRASIL. Constituição (1988) Constituição da República Federativa do Brasil. Brasília: Senado, 1988. $116 \mathrm{p}$.

BRASIL. Lei no 9.394, de 20 de dezembro de 1996. Dispõe sobre as diretrizes e bases da educação nacional. Diário Ofical da União, Brasília, 23 dez 1996. Disponível em: $<$ https://presrepublica.jusbrasil.com.br/legislacao/109224/lei-de-diretrizes-e-baseslei-9394-96>. Acesso em: 14 jul. 2019.

FILHO, Itamir Barroca; AQUINO, Gibeon; ROSA, José Guilherme Santa. II Congresso Brasileiro de Informática na Educação (CBIE 2013). In: XXIV Simpósio Brasileiro de Informática na Educação (SBIE 2013), SIGAA Mobile - O caso de sucesso da ferramenta de gestão acadêmica na era da computação móvel.

LOPES, Nathana Maria Carvalho et al. Congresso Internacional de Educação e Tecnologias: Encontro de Pesquisadores em Educação a Distância. 2018, [S.I.]. 
Avaliação da eficácia e utilização do sigaa na formação discente: estudo de caso nos cursos de licenciatura da UFPI, Campus de Parnaíba. 26/06 a 13/07/2018.

SEVERINO, Antônio Joaquim. Metodologia do Trabalho Científico. $23^{\underline{a}}$ ed. São Paulo: Cortez, 2007.

SOUZA, Maria Naires Alves de; MONTEIRO, André Jalles. Os docentes da Universidade Federal do Ceará e a utilização de alguns dos recursos do sistema integrado de gestão de atividades acadêmica (SIGAA). Ensaio: aval. pol. públ. Educ., Rio de Janeiro, v. 23, n. 88, p. 611-630, jul./set. 2015.

UFRN recebe homenagem pela criação do Sigaa. Disponível em $<$ https://macaibanoar.com.br/ufrn-recebe-homenagem-pela-criacao-do-sigaa/> Acesso em: 14/06/2019.

Enviado: Outubro, 2019.

Aprovado: Maio, 2020. 